\title{
A History of Forests and Climate Change under the IPCC
}

$\mathrm{T}_{\mathrm{h}}^{\mathrm{h}}$ he Intergovernmental Panel on Climate Change (IPCC) was established in 1988 by two United Nations agencies, the World Meteorological Organization and the UN's Environment Programme, to "assess the scientific, technical and socioeconomic information relevant for the risk of human-induced climate change". Its first assessment report in 1990 was the basis for the UN Framework Convention on Climate Change (UNFCCC). For more than twenty years the IPCC has remained the most important source of scientific, technical and socioeconomic information for the Convention. The relationship between the UNFCCC and the IPCC is regarded by the international community as a "model for interaction between science and decision makers".

In its Fourth Assessment Report in 2007, the IPCC noted that about $20 \%$ of anthropogenic carbon dioxide emissions during the 1990s came from land use changes, primarily from deforestation, although $25 \%$ of the total emissions may have been absorbed by terrestrial ecosystems. Depending on the age of the forest, management regime and other disturbances (insects, fire), forests may be reservoirs of carbon, sinks (removing greenhouse gases (GHGs) from the atmosphere), or sources of GHGs. At the same time, IPCC recognized that forests provide essential services, for example, as sources of biological diversity and regulators of hydrological cycles. Reducing deforestation and the resultant land degradation and improving forest cover were considered critical for mitigation and adaptation to climate change.

Forests under the UNFCCC are considered both sinks and sources of GHGs, particularly $\mathrm{CO}_{2}$ emissions. All countries (that signed off on the Kyoto Protocol) were required to count their emissions and removals from land use changes and forestry in their national inventories. Under the Kyoto Protocol, adopted in 1997 and entered into force in 2005, industrialized countries with emission reduction commitments (known as Annex 1 countries) could count their reduction target emissions and removals of GHGs from certain human-induced land use changes and forestry activities, including removal from afforestation (the planting of new forests on lands without forests for at least 50 years) and reforestation (limited to lands that did not have a forest cover on $31^{\text {st }}$ December, 1989); emissions from deforestation; and possible emissions and removals from forest management, cropland and grazing land management, and re-vegetation.

In addition, project-based activities under two mechanisms of the Kyoto Protocol-Joint Implementation (JI) and the Clean Development Mechanism (CDM) - could also result in removals by sinks that would count towards an industrialized country's reduction commitments. Joint Implementation refers to projects undertaken jointly by two Annex 1 countries; all projects in developing countries are under the CDM. Afforestation and reforestation projects were permitted in the first commitment period under the CDM, and project activities had to address issues such as non-permanence, uncertainty, and the risk of leakage. In addition, there was a ceiling on the maximum number of carbon credits that an Annex 1 party could gain this way.

At the Conference of the Parties 11 (COP 11-the eleventh since 1988) in Montreal in 2005, forests were included as a new agenda item under the UNFCCC as "Reducing Emissions from Deforestation in Developing Countries: Approaches to Stimulate Action". Workshops were held on this in 2006 in Rome and again in 2007 in Cairns, Australia. Discussions continued at COP 13 in Bali, which addressed "enhanced national and international action on climate change mitigation". As negotiations proceeded on a financial mechanism to compensate developing countries for maintenance of carbon stocks, three programs emerged for what a financial mechanism would cover: reducing emissions from deforestation and forest degradation in developing countries (REDD); conservation, sustainable management of forests and stock enhancement in addition to REDD (REDD+); and all terrestrial carbon in addition to REDD+ (REDD++). Since COP 13 a program of work has developed on methodological issues related to policy approaches and positive incentives aimed at REDD. A UNFCCC workshop in Tokyo in June 2008 generated agreement that discussions of policy approaches and positive incentives could be initiated based on current knowledge.

At COP 16 in Cancun, Mexico in 2010, REDD+ was formally added to the international climate change regime based on the decision to encourage developing countries to assist in mitigation efforts by undertaking REDD+. This would happen in three phases: development of national strategies or action plans; implementation of policies and measures; and payment for performance on the basis of quantified forest emissions and removals. Discussions on the different financing options for REDD+ were put over to COP 17 in Durban, South Africa.

However, two researchers at Oxford University "strongly felt that the world community was underestimating the importance of forests in mitigating carbon emissions", and as a result of their efforts, "Forest Day" as a side event of the broader UNFCCC agenda was initiated in 2007. The researchers saw "a glaring need for the latest forestry research and thinking to inform global policy makers and UNFCCC negotiators". What they did not foresee was that "Forest Day" would become one of the most influential global events on forests and climate change. Each "Forest Day" since 2007 has been convened by the Center for International Forestry Research (CIFOR) based in Indonesia.

The first "Forest Day" was a major event in Bali, Indonesia at COP 13, December 2007. More than 800 people attended: scientists, members of national delegations, and representatives of intergovernmental and nongovernmental organizations. A major feature was four parallel panel discussions on themes related to forests and climate change. These examined issues 


\section{Canada's Forest Sector at a Turning Point}

\section{The Canadian Woodlands Forum - The Canadian Institute of Forestry \\ L'Ordre des ingén ieurs forestiers du Québec}

invite you to attend the

\section{Annual General Meeting and Conference Québec, Québec

\section{Conference Highlights}

Monday, September 17, 2012

- Pre-Conference Tour - Hardwood

Silviculture (Duchesnay Forest) (Cost \$75.00)

- Student Quiz Bowl

Tuesday, September 18, 2012

- Registration

- Welcome and Opening Remarks

- Keynote Speakers and Plenary Session

- $\quad$ Banquet - Demo International ${ }^{\circledR} 2012$

Launching and OIFQ Awards

- Afternoon Concurrent Sessions

- Reception and Poster Session
Wednesday, September 19, 2012

- Annual General Meetings of CIF/IFC and OIFQ

- Concurrent Morning Sessions

- CIF/IFC Awards Banquet

- Concurrent Afternoon Sessions

Thursday, September 20, 2012 - Optional Field Tours

- An Architectural Tour of Wooden Buildings in Quebec City Cost included in registration (space is limited)

- Gourmet Tour of the Île d'Orléans (Cost \$75.00)

- DEMO International ${ }^{\circledR}$ Exposition 2012 - North America's largest and unique outdoor equipment show (Cost included in registration)

\section{Keynote Speakers}

The 2012 Conference Organizing Committee is proud to present our three keynote speakers, specifically:

1. From Historical Profitability Towards the Future Competitiveness of Quebec's Forest Sector

Michel Vincent, Senior Economist, Director of Economic Service Del Degan Massé (DDM), Québec City, Québec.

2. First Nations Forestry:Will Canada Miss the Opportunity?

Ronald S. Trosper, Head and Professor, American Indian Studies, University of Arizona,Tucson, Arizona

3. Ecosystem Management of Federal Forests in the Pacific Northwest:

A New Approach is Needed!

Normand K. Johnson, University Distinguished Professor, Department of Forest Ecosystems and Society, Oregon State University, Corvallis, Oregon.

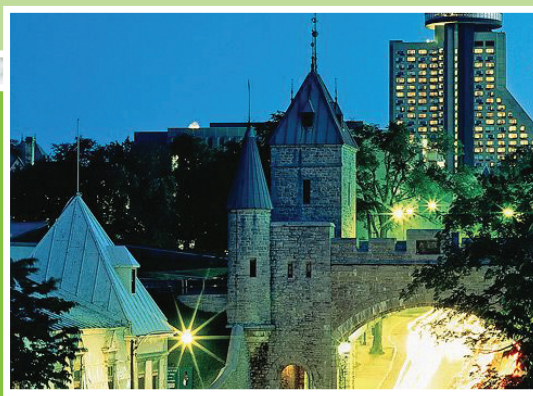

To reserve your hotel room and obtain the room rate of $\$ 185.00$ (plus tax) - quote Group Code PRE1 79 Phone: 1-800-463-5256

E-mail:leconcordereservations@loewshotels.com Room rates guaranteed until August 14, 2012.

\section{Register Now!!}

For more information, please check out our Web site: bttp://democonference.cwfcof.org/

\begin{tabular}{lcc}
\hline Rates & $\begin{array}{c}\text { Early Bird } \\
\text { (before Aug. 31) }\end{array}$ & $\begin{array}{c}\text { Regular } \\
\text { (after Aug. 31) }\end{array}$ \\
\hline
\end{tabular}

Full Program

Members (CWF,

CIF/IFC and OIFQ) $\quad \$ 400 \quad \$ 460$

Non-members $\quad \$ 470 \quad \$ 530$

Retired $\$ 350 \quad \$ 410$

Students $\$ \mathbf{\$ 2 7 5} \quad \$ 335$

Day Pass $\quad \$ 250 \quad \$ 300$

Contact Us

Peter Robichaud, CWF, Co-Chair, Demo International Conference probichaud@cwfcof.org

Sylvie Carles, CIF/IFC, Co-Chair, Demo International Conference Sylvie.Carles@RNCan-NRCan.gc.ca 

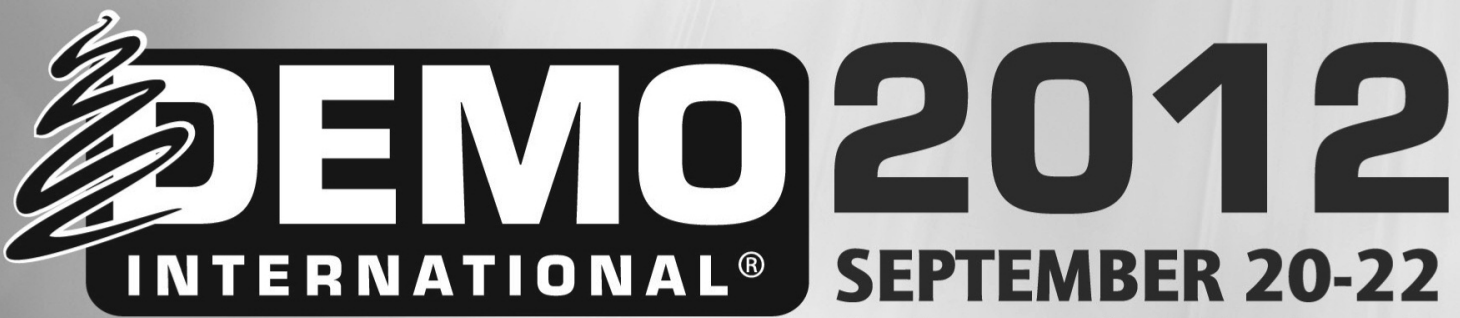

SEPTEMBER 20-22

St. Raymond, QC $\bullet$ Canada

Owned \& Presented by

Canadian Woodlands Forum

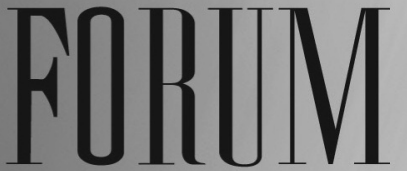

Forum canadien

des opérations forestières
Hosted by

SOLIFOR

Don't miss the Demo International ${ }^{\circledR}$ Bonference
Produced by

MV Master

September 17-20, 2012 at the Loews Le Concorde Hôtel in Quebec City, sponsored by the Canadian Woodlands Forum and the Canadian Institute of Forestry in association with the Ordre des ingénieurs forestiers du Québec.

Visit http://democonference.cwfcof.org for details!

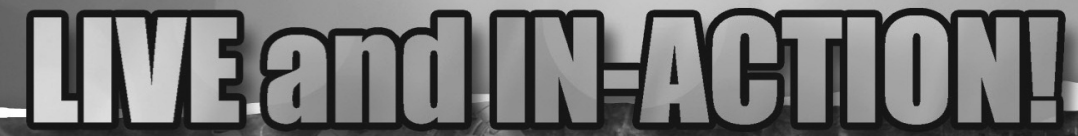

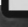

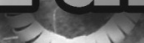

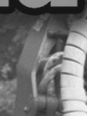
En
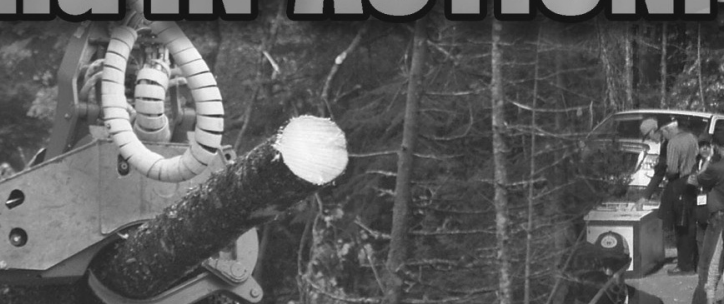
such as setting baselines and methodological challenges in estimating forest carbon; markets and governance challenges associated with REDD+; adaption of forests to climate change; and equity-efficiency trade-offs.

"Forest Day 2" in Poznan, Poland in 2008 (COP 14) had a few more participants and looked at addressing forest degradation through sustainable forest management, capacity-building for REDD, and options for integrating REDD into the global climate regime.

"Forest Day 3" in 2009 in Copenhagen brought together 1600 participants to consider challenges with REDD+. (How difficult it must be for 1600 people to consider anything!). Various global views on forests and climate change were presented and workshops covered issues related to the measuring and monitoring of baselines and leakages; financing for forests and climate change; the potential social effects of REDD initiatives; and landscape approaches to mitigation and adaption.

"Forest Day 4" in Cancun, Mexico (COP 16) in December 2010 had, as its theme, "Time to Act". It highlighted the urgency to ensure the protection of the world's forests and their biodiversity. Workshops covered topics such as optimizing the multiple benefits of Sustainable Forest Management and REDD+; promoting synergies between climate change mitigation and adaption across forest landscapes; and land use, land use change and forestry.

"Forest Day 5" 2011 in Durban, South Africa saw more than 1100 people from 82 countries in attendance. The theme "From Policy to Practice", aimed "to inform the COP agenda and forest stakeholders on ways to implement the REDD+ agreement to produce social and environmental benefits and to integrate forests into adaptation strategies on the ground". Organizers gave special attention to issues relevant to sub-Saharan Africa, to REDD+ issues facing the humid tropical forests of the Congo Basin, and to the improved management of Africa's dry forests. The link between forests and food security was one of the main themes of the workshop.

The next "Forest Day 6" as part of COP 18 will be held in Doha, Qatar in December, 2012. (It is somewhat ironic to be discussing forestry issues in a desert kingdom but doesn't seem to concern the UNFCCC.) The event will consider issues ranging from REDD+ financing to adaption, desertification, reforestation and afforestation.

On a personal note: it is my perception from tracking much of the flutter and chatter around the IPCC, the UNFCCC, and all of the various COPs over the years that Canada is not "at the table"; it is minimally involved. We have nothing to say; nothing to champion. Canada was instrumental in the creation of the International Center for Agroforestry Research; we were ini- tially very involved in the establishment of CIFOR (Center for International Forestry Research) in Indonesia. Canada, as a major forestry country, has been quiet, missing in action and has allowed others to take the lead role (the Australians, the Japanese, the Americans and a host of Europeans).

Is my perception of Canada's indifference to global affairs correct?

Sources: IRIN News etc. Ron Ayling, Editor-in-Chief The Forestry Chronicle

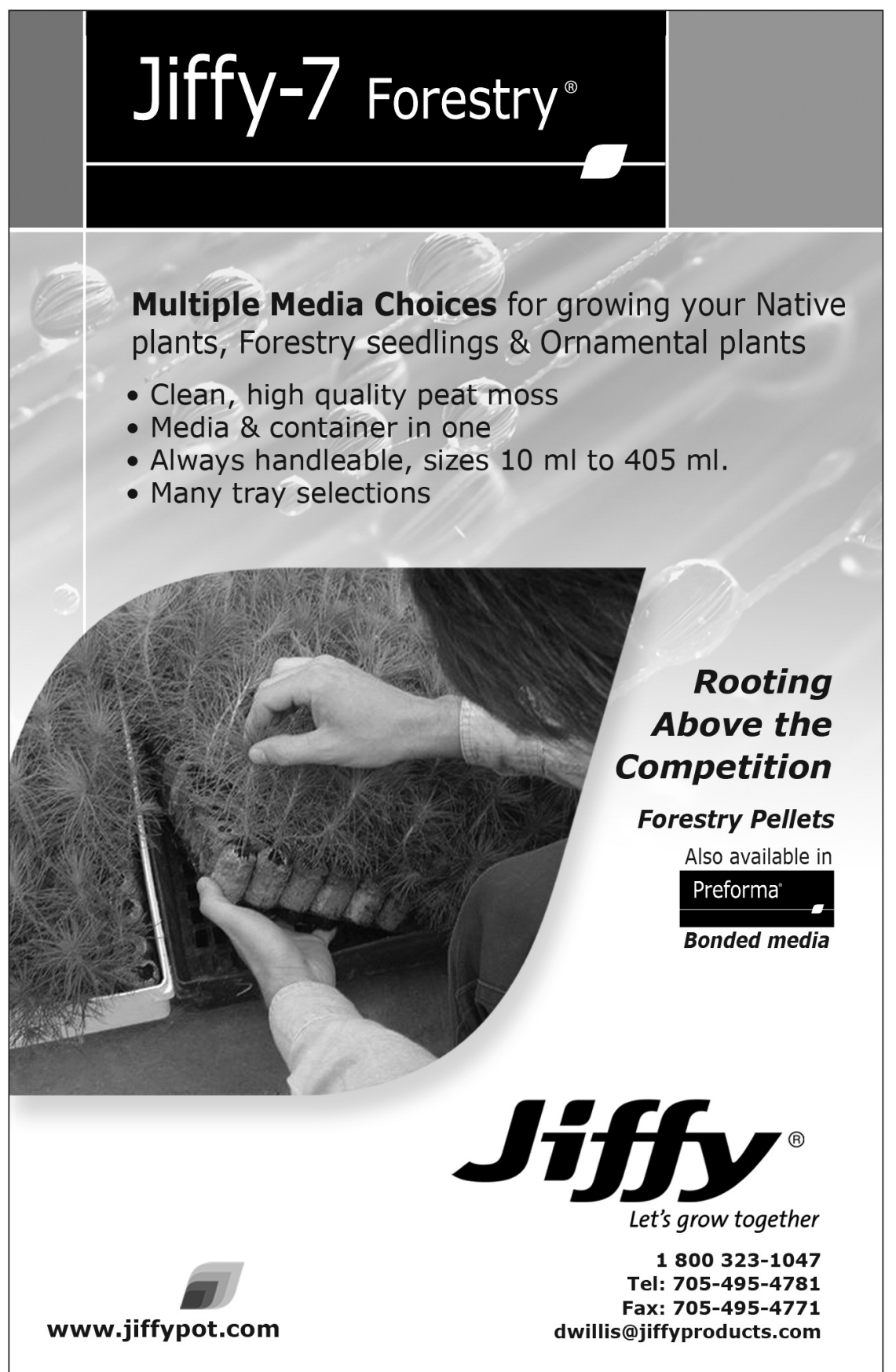

